\title{
Philosophiques
}

\section{Une contribution à l'histoire de la philosophie au Québec}

\section{Fernand Dumont}

Volume 10, numéro 1, avril 1983

URI : https://id.erudit.org/iderudit/203216ar

DOI : https://doi.org/10.7202/203216ar

Aller au sommaire du numéro

Éditeur(s)

Société de philosophie du Québec

ISSN

0316-2923 (imprimé)

1492-1391 (numérique)

Découvrir la revue

Citer cet article

Dumont, F. (1983). Une contribution à l'histoire de la philosophie au Québec. Philosophiques, 10(1), 119-125. https://doi.org/10.7202/203216ar d'utilisation que vous pouvez consulter en ligne.

https://apropos.erudit.org/fr/usagers/politique-dutilisation/ 


\title{
UNE CONTRIBUTION À L'HISTOIRE DE LA PHILOSOPHIE AU QUÉBEC
}

\author{
par Fernand Dumont
}

L'excellent ouvrage d'Yvan Lamonde sur La philosophie et son enseignement au Québec (1665-1920) ${ }^{1}$ appelle sans aucun doute diverses lectures. J'aimerais proposer quelques remarques en marge de celle que $j$ 'ai poursuivie.

À première vue, cette monographie érudite ne nous apprend rien de très nouveau sur le passé de notre culture. Contrôle progressif exercé sur les idéologies par le clergé et l'Église à mesure que celle-ci affirmait son emprise sur notre société, «romanisation » de la pensée officielle, systématisation des énoncés qui confine au dogmatisme : nous savions tout cela avant d'ouvrir ce livre. L'auteur lui-même risque de nous égarer quand il paraît parfois ne voir, dans les résultats de ses analyses, que la confirmation d'un diagnostic largement répandu. Serions-nous donc devant un document supplémentaire qui s'ajouterait à un dossier d'études sur les idéologies québécoises désormais sans surprise? Je ne le crois pas.

Pour le mieux marquer, je reviens à quelques remarques élémentaires sur l'examen des idéologies.

Si l'on peut isoler (d'une manière relative, certes) les idéologies dans l'ensemble des phénomènes culturels, c'est qu'elles constituent des discours particulièrement articulés - des textes, dira-t-on, si l'on veut bien prendre le mot dans un sens à la fois strict et élargi. Cela permet de dégager à partir des idéologies, mieux que pour l'ensemble d'une culture, des thématiques, des

1. Hurtubise $\mathrm{HMH}, 1980$. À compléter par un article du même auteur : " L'histoire de la philosophie au Canada français (de 1920 à nos jours) : sources et thèmes de recherche ", Philosophiques, VI, 2, octobre 1979, 327-339. 
structures, et de les reporter aux pouvoirs et à la division du travail social. D'où le privilège, méthodologique tout au moins, qu'on accorde aux idéologies dans les investigations sur les cultures. Privilège tout relatif, j'y insiste, et qui relève de premières démarches ; car les arrangements auxquels procèdent les discours idéologiques ne sauraient être considérés comme une espèce de résumé de la culture. Le travail des intellectuels et des pouvoirs y est trop visible pour qu'on le prenne pour une conception de la société par elle-même. Les idéologies éclairent moins l'ensemble d'une société qu'elles ne révèlent les images que veulent en proposer - ou en imposer - ceux qui détiennent les moyens de le faire. Aussi est-il difficile de mesurer la portée de ces discours, de circonscrire leurs publics, d'évaluer le statut des idéologues, de déceler les liens des discours entre eux.

Heureusement, parmi tous ces discours, il en est certains qui invitent à resserrer l'analyse. On mesure davantage leur diffusion, on connaît plus précisément les organisations qui les portent ; on conçoit avec plus de netteté à quel point ils se sont voulus fondements de culture. À des époques où les programmes scolaires étaient plus minutieusement confectionnés qu'aujourd'hui et faisaient l'objet de contrôles et d'examens plus systématiques et plus larges, les manuels constituaient des discours de ce genre. Ils n'ont jamais été les seuls : on pense aux codes juridiques, aux prescriptions techniques, aux traités de théologie, à bien d'autres documents analogues. Mais les manuels on: un intérêt singulier : ils s'adressent à l'enfant et à l'adolescent, dans des phases décisives de leur socialisation. Leur contenu ne retiendra pas nécessairement l'acquiescement dans le jeune âge ou par la suite; même pour les oppositions les plus vives, ils seront objets de polémiques qui leur conserveront un poids certain. Il n'est pas indifférent, pour ceux de ma génération, quel que fut leur cheminement ultérieur, d'avoir mémorisé le Petit catéchisme, l'Histoire du Canada de Farley et Lamarche ou le Manuel de philosophie de Mgr Grenier.

Le manuel résumait la «table de la loi »; il constituait le compendium de schémas et de lieux communs que diffusaient ou contestaient, d'une façon plus vaste et plus coulante, d'autres discours idéologiques. En plus d'avoir été ainsi inséré dans un système d'apprentissage, dont il représentait comme un micro- 
cosme, le manuel était l'instrument premier d'accès au baccalauréat, c'est-à-dire à un symbole fondamental d'un statut social éventuel.

$$
* *
$$

C'est dans cette perspective que, pour ma lecture, le livre d'Yvan Lamonde prend toute sa portée.

Sans doute, il confirme ce que nous savions de l'allure d'ensemble des idéologies dites « conservatrices» d'antan. Il incite surtout à mieux comprendre comment certains pouvoirs et certains idéologues ont tenté de donner fondement - j'oserais dire axiomatique - à des idéologies autrement plus dispersées. Il permet d'observer davantage comment cette quête des fondements fut liée étroitement à l'emprise progressive du pouvoir.

Yvan Lamonde souligne que, dès les origines, en NouvelleFrance, l'enseignement de la philosophie est lié étroitement à celui de la théologie. Il est déjà une sorte de scolastique. J'aurais aimé que l'auteur ne se borne pas à des parallèles avec l'enseignement des collèges en France, à la même époque ; qu'il fit quelque allusion à ce qui, en Europe, séparait la philosophie des collèges et le mouvement philosophique. Nous sommes au moment où disputent et écrivent Descartes, Pascal, Malebranche . . . Bien entendu, s'il y avait place pour un enseignement des philosophies de collège en Nouvelle-France, il ne pouvait être ici en contradiction avec un mouvement philosophique autochtone. Mais cette absence de contrepartie aura des conséquences plus tard, aux siècles suivants, quand à cette philosophie des collèges s'opposera une «philosophie de l'opinion». De cette dernière, Lamonde marque fort bien les conditions d'émergence. Avec les institutions parlementaires, les journaux, les bibliothèques, paraissent et se confirment à la fois une bourgeoisie "éclairée » et une sphère de l' « esprit public ", comme on disait en ce temps-là.

Dès lors se confrontent une «philosophie de professeur » et ce que j'appelais une "philosophie de l'opinion». Car ce sont moins des systèmes qui se heurtent que des conceptions portant sur les enracinements sociaux de la spéculation philo- 
sophique. Je retiens, à titre d'illustration, deux textes que cite Yvan Lamonde. Le premier est publié dans la Gazette de Québec du 31 mars 1791: «Il y a à présent seize mois que les Français vivent sous un gouvernement libre, et jouissent de la liberté de presse, et dans ce court espace la raison a fait plus de progrès, et les esprits se sont plus éclairés qu'ils n'auraient probablement fait durant un siècle avant la Révolution ». Le second texte paraît en 1791 dans la Gazette de Montréal : "Il ne faut pas que le ciseau de la superstition et de la théologie ronge les ailes du Génie - non il est absolument nécessaire que les hommes se servent de la raison que Dieu leur a donnée pour guide, qu'ils examinent tout, qu'ils cherchent sans cesse à découvrir la vérité qui peut seule faire le bonheur de leur existence ".

On saisit mieux, dans ce contexte, un enjeu qui ne concernait pas seulement notre société. Il renvoie à un immense débat qui la débordait de toutes parts. La " philosophie des lumières " en appelait à l'opinion, à l'esprit public dont la bourgeoisie ouvrait partout la voie. La pensée catholique européenne du début du XIX ${ }^{\mathrm{e}}$ siècle, en voulant la réfuter, en acceptait à tout prendre le postulat : la référence à une opinion, à un consensus dont on cherchait les assises jusque dans les origines du langage. Dès lors, on ne s'étonne pas de la percée de la philosophie de La Mennais (première manière). Lamonde aurait pu souligner davantage à quel point il y a eu alors convergence d'une recherche d'ici avec les grands débats d'Occident.

Par ailleurs, il montre admirablement quelle en fut l'issue. À partir des années 1860 , on assiste à un renforcement du pouvoir de l'Église, qui se traduit par l'augmentation rapide des effectifs du clergé, des effectifs des collèges, qui se révèle aussi dans un encadrement doctrinal, dont une sorte de professionalisation des enseignants de la philosohie est une des conséquences. Le " sens commun », l' « opinion fondée » s'identifient avec le catholicisme en ses aspects les plus institutionnels. "Quand donc, s'écrie un auteur, un trop grand nombre de catholiques instruits du Canada sauront-ils qu'il y a une science catholique, une philosophie catholique, une histoire catholique, des arts catholiques, une morale et j'oserai dire, une religion catholique. »(Mélanges religieux, 17 janvier 1851, cité p. 134). 
L'achèvement du processus fut à la fois d'ici et d'ailleurs. L'Église catholique s'acheminait vers une philosophie officielle, celle de saint Thomas, que sanctionna officiellement l'encyclique de Léon XIII. Lamonde souligne, avec pertinence, que cette encyclique ne fut pas reçue au Québec de façon passive. Elle consacrait, à sa manière, une sorte de mouvement interne, la recherche d'une unanimité. Les conditions sociologiques étaient en place pour que cette philosophie de sens commun devienne le sens commun des collèges - et d'une société. Il y fallut un effort d'uniformisation des programmes, des manuels, une centralisation des institutions dont Lamonde raconte l'histoire.

L'auteur prolongera son récit dans un autre ouvrage, souhaitons-le. Mais à la date où il s'arrête, était achevée pour l'essentiel la mise en place des conditions de l'enseignement de la philosophie. Bien plus tard, ceux de ma génération n'ont pas fait autrement leur premier apprentissage de la philosophie qu'en butinant, dans le manuel de Mgr Grenier entre autres, les derniers vestiges de l'histoire reconstituée dans cet ouvrage.

$$
\text { ** }
$$

Je répète que j'ai lu ce livre à ma manière, avec mes lunettes et en y mettant mes propres questions. Aussi, je noterai rapidement comment ces questions pourraient se prolonger plus loin. Est-il meilleure façon d'étudier un ouvrage qui mérite beaucoup d'attention?

Ces prolongements éventuels je les ramènerai, un peu arbitrairement, à trois principaux.

1. Lamonde, je l'ai remarqué, ne manque pas de mettre en relation l'histoire de la philosophie scolaire en notre pays avec le plus large mouvement des idées au Québec et ailleurs. Il me semble qu'il reste à explorer plus à fond ces lieux, ces jeux d'influences et d'assimilations. Ainsi, la référence à un Moyen Âge mythique, qui fut si importante au dix-neuvième siècle, a inspiré mais a débordé aussi de toutes parts le triomphe de Thomas d'Aquin. Elle relève d'un vaste débat de l'Occident où se sont emmêlés les courants les plus divers. Il s'agissait, dans la mouvance accélérée de l'histoire, de se donner une conscience 
historique. Exalter le Moyen Âge ou le dénigrer pour comprendre l'incertain $\mathrm{XIX}^{\mathrm{e}}$ siècle, pour le situer dans une évolution et un destin : de droite et de gauche, de Chateaubriand à Michelet, en passant par tant d'autres, que de tâtonnements où la lecture du passé était aussi une lecture du présent ${ }^{2}$. Un ample regard sur la pensée québécoise de jadis, à qui n'échapperait aucune des composantes principales de la pensée occidentale d'alors, permettrait de mieux appréhender le champ où ont été élus les choix que décrit Lamonde. Il entraînerait aussi à mieux ressentir la dramatique de ces choix, de sorte que paraîtrait plus complexe le dossier conventionnel sur ce passé que les monographies, en s'accumulant, semblent un peu trop confirmer. N'est-ce pas, après tout, la vertu de la recherche que de ne point se borner à introduire dans un dossier historique de nouvelles pièces à convictions, de faire sourdre des questions qui bousculent les belles ordonnances?

2. Grâce au matériau qu'il analyse, Lamonde fournit un point de départ pour examiner à nouveau la crise du catholicisme québécois à partir des années 60 . En tout cas, i'y trouve aliment pour une hypothèse qui m'est chère. Le catholicisme d'ici s'est effondré brusquement, après un règne apparemment tout puissant ; on s'étonne parfois de ce paradoxe. Je crois, pour ma part, qu'il n'a rien de surprenant, à condition de chercher la cause de l'effondrement moins dans les années dernières que dans les années triomphantes d'avant. La systématique idéologique que reconstitue Lamonde est exemplaire de l'idéologie religieuse plus vaste ; elle en montre, par son resserrement, la précarité. La pensée religieuse était devenue un code des enseignements officiels ; elle trahissait ainsi non pas seulement sa distance par rapport aux contestataires de l'Église, mais aussi sa distance, au-dedans de l'Église, entre un enseignement tout formel et les exigences de l'action effective et de la sensibilité des chrétiens.

On saisit mieux, sous cet éclairage, les tentatives de la Relève, de Cité libre, de Maintenant pour détendre ces systèmes, pour manifester plus librement et par des pensées de compromis

2. Belle vue d'ensemble dans un article récent de Pierre Vallin : "Le Moyen Âge, aujourd'hui ", Études, 356, 4, avril 1982, 481-496. Voir aussi, dans une bibliographie immense, Jürgen Voss : "Le problème du Moyen Âge dans la pensée historique en France (XVI"$\mathrm{XIX}^{\mathrm{e}}$ siècles)", Revue d'bistoire moderne et contemporaine, 1977, 321-340. 
ces exigences d'action et de sensibilité. Et on entrevoit mieux les causes de leur échec.

3. Dans la ligne de mes réflexions de départ sur l'importance des manuels et des codes pour l'étude des idéologies, le livre de Lamonde devrait être mis en regard d'autres cas du même genre. Le hasard de l'édition nous fournit un bel exemple, cette fois pour l'enseignement de la littérature canadienne-française. Dans une thèse de maîtrise, Lucie Robert étudiait récemment la structure du manuel de Mgr Camille Roy, son évolution selon les éditions successives ${ }^{3}$. On y voit se constituer l'espace littéraire québécois comme référence pour les jeunes générations durant un demi-siècle. Comment ne pas rapprocher ce phénomène idéologique de celui qui a retenu l'attention de Lamonde?

À mesure qu'elles se multiplieront, ces monographies, apparemment anodines et confinées à l'érudition patiente, apporteront une contribution décisive à un immense phénomène que j'appelle, pour ma part, l'institutionnalisation de la culture. C'est là un des grands problèmes de notre temps, un des grands courants qui l'animent. À la culture dispersée dans la vie quotidienne fait de plus en plus place la culture fabriquée, sublimée dans des univers superposés où sont à l'œuvre des pouvoirs, des organisations, des intellectuels, des modes et des codes. L'institutionnalisation de la culture par l'Église, les collèges, les professeurs, dont Yvan Lamonde et Lucie Robert nous offrent de minutieux examens, est un cas qu'il faut désormais replacer dans un contexte infiniment plus large, celui du destin de la culture. Les agents, les pouvoirs, les modes et les codes ont changé depuis le manuel de Mgr Grenier et celui de Mgr Roy ; loin de disparaître, le phénomène est devenu partout présent dans sa dispersion même. Il y a donc profit immense à s'attarder à des cas qui, loin d'achever une histoire dépassée, préfiguraient l'histoire d'aujourd'hui. À condition de ne pas renvoyer à la vaine curiosité historique ce qui, au contraire, nous interroge au plus près de notre actualité.

Département de sociologie

Université Laval

3. Lucie Robert : Le manuel d'historre de la littérature canadienne de Mgr Camille Roy, thèse publiée par l'Institut québécois de recherche sur la culture, 1982. 